\title{
Assessment of Vineyard Water Status by Multispectral and RGB Imagery Obtained from an Unmanned Aerial Vehicle
}

\author{
Patricia López-García, ${ }^{1}$ Diego S. Intrigliolo, ${ }^{2}$ Miguel A. Moreno, ${ }^{1}$ \\ Alejandro Martínez-Moreno, ${ }^{2}$ Jose F. Ortega, ${ }^{1}$ Eva P. Pérez-Álvarez, ${ }^{2}$ \\ and Rocío Ballesteros ${ }^{1 *}$
}

\begin{abstract}
Multispectral and conventional cameras (red, green, blue [RGB] imager) onboard unmanned aerial vehicles (UAVs) provide very high spatial, temporal, and spectral resolution data. To evaluate the capacity of these techniques to assess vineyard water status, we carried out a study in a cv. Monastrell vineyard located in southeastern Spain in 2018 and 2019. Several irrigation strategies were applied, including different water quality and quantity regimes. Flights were performed using conventional and multispectral cameras mounted on the UAV throughout the growth cycle. Several visible and multispectral vegetation indices (VIs) were determined from the images with only vegetation (without soil and shadows, among others). Stem water potential was measured by pressure chamber, and the water stress integral $(\mathrm{S} \psi)$ was obtained during the season. Simple linear regression models that used VIs and green cover canopy (GCC) to predict $\mathrm{S} \psi$ were tested. The results indicate that visible VIs best correlated with $\mathrm{S} \psi$. The green leaf index (GLI), visible atmospherically resistant index (VARI), and GCC showed the best fits in 2018, with $\mathrm{R}^{2}=0.8,0.72$, and 0.73 , respectively. When the best model developed with the 2018 data was applied to the 2019 data set, the model fit poorly. This suggests that on-ground measurements of vine stress must be taken each growing season to redevelop a model that predicts water stress from UAV-based imaging.
\end{abstract}

Key words: multispectral images, RGB images, stem water potential, UAV, vineyard, water stress

Grapevine water status is a major determinant for vine performance and wine composition (Jackson and Lombard 1993) and is potentially affected by many soil and environmental factors interacting with the vine physiology and the vineyard management. In arid and semiarid areas, irrigation (i.e., the watering regime and its salinity level) plays an important role in determining vine water status (Mirás-Avalos and Intrigliolo 2017).

Efforts have therefore been made to improve water use efficiency and crop yields, moving toward a more sustain-

\footnotetext{
${ }^{1}$ Instituto de Desarrollo Regional (IDR), Universidad de Castilla-La Mancha, Albacete, Spain; and ${ }^{2}$ Centro de Edafología y Biología Aplicada del Segura. Consejo Superior de Investigaciones Científicas (CEBAS-CSIC), Murcia, Spain.

*Corresponding author (Rocio.Ballesteros@uclm.es)

Acknowledgments: This research was funded by Ministry of Science, Innovation and Universities, grant numbers RTC-2017-6365-2, AGL2017-82927C3-2-R, and AGL2017-83738-C3-3-R; and by the Government of Castilla-La Mancha, grant number SBPLY/17/180501/000251. The authors acknowledge the funding from Ministry of Science, Innovation and Universities with a University Teaching Scholarship (Formación de Profesorado Universitario, FPU). The authors also wish to thank the commercial vineyard owner-the Water User Association "Las Colleras" located in Fuente-Álamo, Albacete, Spain - and the field technicians for their work and involvement in the trial.

Manuscript submitted Oct 2020, revised Jan 2021, March 2021, accepted March 2021

This is an open access article distributed under the CC BY license (https:// creativecommons.org/licenses/by/4.0/).

By downloading and/or receiving this article, you agree to the Disclaimer of Warranties and Liability. The full statement of the Disclaimers is available at http://www.ajevonline.org/content/proprietary-rights-notice-ajev-online. If you do not agree to the Disclaimers, do not download and/or accept this article. doi: 10.5344/ajev.2021.20063
}

able agricultural water management. The concept of precision viticulture seeks to describe the in-plot vineyard spatial variability to provide recommendations with the objective of improving management efficiency in terms of quality, production, and sustainability (Matese and Di Gennaro 2015). One of the techniques that pursues sustainable agricultural water management is regulated deficit irrigation (RDI), which consists of replacing only part of the potential grapevine evapotranspiration during some previously established phenological periods. Therefore, RDI is a standard practice in Mediterranean viticulture as an effective means of regulating the water status of grapevines under a pressing water scarcity scenario (Romero et al. 2010). The effect of RDI depends on vine phenological stage and plant water stress, as generated by water restrictions and soil and climatic conditions. The application of RDI can mitigate the negative effects of climate change on grapevine productivity and fruit ripening (Buesa et al. 2017) while ensuring the sustainable use of water resources.

Implementation of proper RDI strategies demands the monitoring of grapevine water status; there are different methods to achieve this goal. These include i) a more direct determination of plant water status, such as stomatal conductance, stem water potential $\left(\Psi_{\text {stem }}\right)$, leaf water potential, predawn leaf water potential $\left(\Psi_{\mathrm{pd}}\right)$, and carbon isotope composition measurements; and ii) sensor monitoring systems collecting a large number of indirect measurements over a period of time, such as transpiration measurements, trunk diameter fluctuations, and leaf and canopy temperatures (Acevedo-Opazo et al. 2008a). Some authors have proposed midday $\Psi_{\text {stem }}$ measurements as a significant physiological indicator of water status for irrigated and rainfed grapevines (Acevedo-Opazo et al. 2010). These 
measurements are manual, time-consuming, and may be unrepresentative of the spatial variability of water status over the whole farm.

There are many available tools used for precision viticulture. One of them is remote sensing imagery data from satellites, airplanes, balloons, helicopters, and unmanned aerial vehicles (UAVs) (Boukoberine et al. 2019) to collect spatial data. UAVs with lightweight, high-quality geometric and radiometric sensors allow users to obtain very high spatial (centimetric) and temporal resolution data (Pádua et al. 2017). Spectral reflectance data from onboard sensors have been used to monitor biochemical and biophysical attributes, such as biomass, leaf pigment contents, canopy water status, crop coefficient, and crop evapotranspiration (Zarco-Tejada et al. 2005, Acevedo-Opazo et al. 2008a, Berni et al. 2009, Baluja et al. 2012, Ballesteros et al. 2015). Spectral data are usually employed as a mathematical combination of two or more bands to generate vegetation indices (VIs) based on visible or red, green, blue (RGB), red-edge, and near infrared (NIR) regions of the electromagnetic spectrum, among others (Pôças et al. 2015, Romero et al. 2018). The visible part of the spectrum is characterized by low reflectance, due to the strong absorption of foliar pigments such as chlorophyll and carotenoids. The NIR region is characterized by high reflectance, and the thermal domain canopy is characterized by its temperature. As stomata close under pressure stress, transpiration stops and leaf temperatures rise. Thus, leaf or canopy temperatures can be used as a predictor of plant stress (Costa et al. 2010). Recent studies to detect grapevine water stress have used thermal measurements obtained from aerial imagery. Some of them used several multispectral VIs, but few used RGB VIs because the visible part of the spectrum is characterized by low reflectance (as mentioned above) (Möller et al. 2007, RodríguezPérez et al. 2007, Rossini et al. 2013, Zarco-Tejada et al. 2013, Pôças et al. 2015). Möller et al. (2007) used thermal and visible

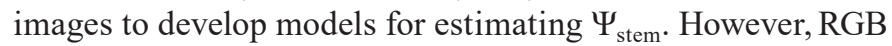
VIs were not computed, and RGB imagery were used only as supporting data. Rodríguez-Pérez et al. (2007), Zarco-Tejada et al. (2013), and Rossini et al. (2013) used the photochemical reflectance index (PRI), which suggests its use is a good indicator for water stress monitoring. PRI uses the 530 and 550 wavelengths of the visible region in the electromagnetic spectrum. Pôças et al. (2015) also used hyperspectral reflectance indices to predict vineyard $\Psi_{\text {pd. }}$.

Most research studies have adapted methodologies developed in traditional remote sensing methods (using satellite imagery), including the utilized VIs and bands. Nevertheless, the enormous increase of spatial resolution has opened new opportunities to use other bands and VIs, primarily focusing on the visible spectrum (Ballesteros et al. 2018). No reported studies have analyzed the use of VIs derived from the visible bands to predict water status, compared with the traditionally used multispectral and thermal VIs. Nevertheless, in this study RGB VIs, in addition to multispectral VIs, were studied as predictors of grapevine water status because of the lower cost of RGB cameras and easier photogrammetric treatment, compared with multispectral and thermal products.
Green cover canopy (GCC) is a geometric parameter that provides information about vegetative growth level or canopy vigor. It can be determined from RGB imagery data and is usually related to the leaf area index (LAI), biomass, plant height, and canopy volume, among others (Ballesteros et al. 2015, 2018). Nevertheless, to the best of our knowledge, it has not yet been shown to be related to vine water status. In this study, we evaluate the relationship between GCC and grapevine water status measurements. The objective of this study was to analyze the use of multispectral and RGB VIs as well as GCC to characterize spatial and temporal variations in vineyard water status. This was done as a first step for future models that will be developed to estimate vineyard water status according to its location and variety, among others. High frequency multispectral and RGB imaging at high spatial resolution were used to determine VIs as potential predictors of vine water status. The proposed methodology is complementary to field determinations with pressure chamber measurements. To obtain a wide range of vine water status conditions, several irrigation regimes were tested-including different water salinity levels - to better take into account different potential sources of variations for vine water status.

\section{Materials and Methods}

Site location and experimental design. The research was undertaken during the 2018 and 2019 growing seasons in a commercial vineyard located in Fuente-Álamo, Albacete, Spain $\left(38^{\circ} 43^{\prime} \mathrm{N}\right.$; $1^{\circ} 28^{\prime} \mathrm{W}$; elevation $820 \mathrm{~m}$ asl; see Figure 1). The soil was sandy loam (55.64\% sand, $27.73 \%$ silt, and $16.63 \%$ clay) with variable depth from 35 to $50 \mathrm{~cm}$. It had $1.2 \%$ organic matter, $47.7 \%$ active calcium carbonate $\left(\mathrm{CaCO}_{3}\right)$, electrical conductivity $(\mathrm{EC})$ of $0.39 \mathrm{dS} / \mathrm{m}, \mathrm{pH}$ of 8.86 , and bulk density of $1.17 \mathrm{~g} / \mathrm{cm}^{3}$. The irrigation water analysis showed an EC of $1.26 \mathrm{dS} / \mathrm{m}$ and $\mathrm{pH}$ of 8.37.

The climate was defined as continental Mediterranean (National Geographic Institute 2020), with hot and dry summers and daily maximum summer temperatures close to $40^{\circ} \mathrm{C}$, mainly in July and August. The weather station was located $10 \mathrm{~km}$ from the experimental plot. Annual rainfall at the experimental site was $406 \mathrm{~mm}$ in 2018 and $550 \mathrm{~mm}$ in 2019, while rainfall from April to September was $230 \mathrm{~mm}$ and $400 \mathrm{~mm}$, respectively. The total annual reference evapotranspiration $\left(\mathrm{ET}_{0}\right)$ was $1171 \mathrm{~mm}$ in 2018 and $1270 \mathrm{~mm}$ in 2019, while $\mathrm{ET}_{0}$ for the growing season was $834 \mathrm{~mm}$ and 879 $\mathrm{mm}$, respectively. Growing degree days (GDD) from April to harvest was computed as the sum of the average daily temperature above a threshold of $10^{\circ} \mathrm{C}$ (Amerine and Winkler 1944). GDD at harvest was 1904 up to 10 Oct 2018, and 1868 up to 7 Oct 2019.

The study was performed in a 0.6 ha subplot of a 6.5 ha commercial vineyard. The vines, planted in 2007, were cv. Monastrell on 110R rootstock. They were planted in northsouth oriented rows and trained to a double Guyot system on a vertical trellis. The row $\times$ vine spacing was $3 \mathrm{~m} \times 1.5 \mathrm{~m}$ (2222 vines/ha). Two 2-bud spurs and two 60 to $90 \mathrm{~cm}$ canes were retained during pruning each year. In July, green shoots 
were trimmed from each grapevine, according to local growing practice. The plot was irrigated with self-compensating dippers spaced by $1 \mathrm{~m}$, with a dripper discharge of $4 \mathrm{~L} / \mathrm{hr}$.

Because of water restrictions under a pressing water scarcity scenario, the annual available water to irrigate was set as $1000 \mathrm{~m}^{3} /$ ha by the water managers in the study area. Six treatments (T1 to T6) and four replicates for every treatment were considered as the experimental design. Every treatment and replicate were randomly placed along the experimental area (Figure 1).

Each replicate involved four rows with 10 vines. The two outer rows and the most external vines of every row were considered as buffers. The characteristics of different treatments were the following: T1 was rainfed, T2 was irrigated with standard-quality water, $\mathrm{T} 3$ was irrigated adding sulfates (sodium sulfate $\left[\mathrm{Na}_{2} \mathrm{SO}_{4}\right]$ and magnesium sulfate $\left[\mathrm{MgSO}_{4}\right]$ ), T4 was irrigated adding sodium chloride $(\mathrm{NaCl})$, and $\mathrm{T} 5$ and T6 were irrigated adding the aforementioned sulfates and $\mathrm{NaCl}$ respectively, but irrigation events started at veraison. Salts were added to T3, T4, T5, and T6 up to irrigation water reaching an EC of $5 \mathrm{dS} / \mathrm{m}$. Irrigation in T2, T3, and T4 began when $\Psi_{\text {stem }}$ reached -0.8 MPa. In the 2019 season, the experimental design was simplified, as T5 and T6 were not applied because agronomic and grape quality differences with the other salted treatments (T3 and T4) were not observed. Because the aim of the present study is to correlate different grapevine water status determinations, the fact that $\mathrm{T} 5$ and T6 were not used for the 2019 data analysis does not affect the robustness of our results.
Grapevine water status measurement. Grapevine water status was assessed by midday $\Psi_{\text {stem }}$ six times in 2018 and seven times in 2019 (Table 1) on two leaves (one leaf per vine) per replicate plot with a pressure chamber (Model 600, PMS Instrument Company). Previous observations showed that the variation in $\Psi_{\text {stem }}$ among leaves of the same grapevines was very low (coefficient of variation lower than 5\%). Therefore, increasing the number of vine measurements instead of increasing the number of $\Psi_{\text {stem }}$ determinations per vine was performed, as measurements have to be carried out within $1 \mathrm{hr}$ (Intrigliolo and Castel 2010). Field determinations for $\Psi_{\text {stem }}$ were carried out on the same days that aerial images were collected (Table 1), and measurements were always carried out on the same selected vines. Indeed, considering the wide range of irrigation treatments explored, vine water status was assessed in a total of 48 and 32 vines in 2018 and 2019, respectively.

$\Psi_{\text {stem }}$ characterizes the grapevine water status at the moment of determination; however, the spectral response of leaves shows the accumulated effect of water deficit duration and intensity from the beginning of the cycle to the moment of determination, represented by water stress integral $\left(\mathrm{S}_{\psi}\right)$, computed as the sum of vine water potential measurements during the study period (Buesa et al. 2017). It was calculated, as in Equation 1, as the summation of the difference of average of two consecutive measurements of $\Psi_{\text {stem }}\left(\bar{\Psi}_{\mathrm{i}, \mathrm{i}+1}\right)$ and the least negative value registered during the season $(\mathrm{c}=-0.35$ $\mathrm{MPa}$ in both seasons), multiplying it by the number of days between one measurement and the next (n). The possible

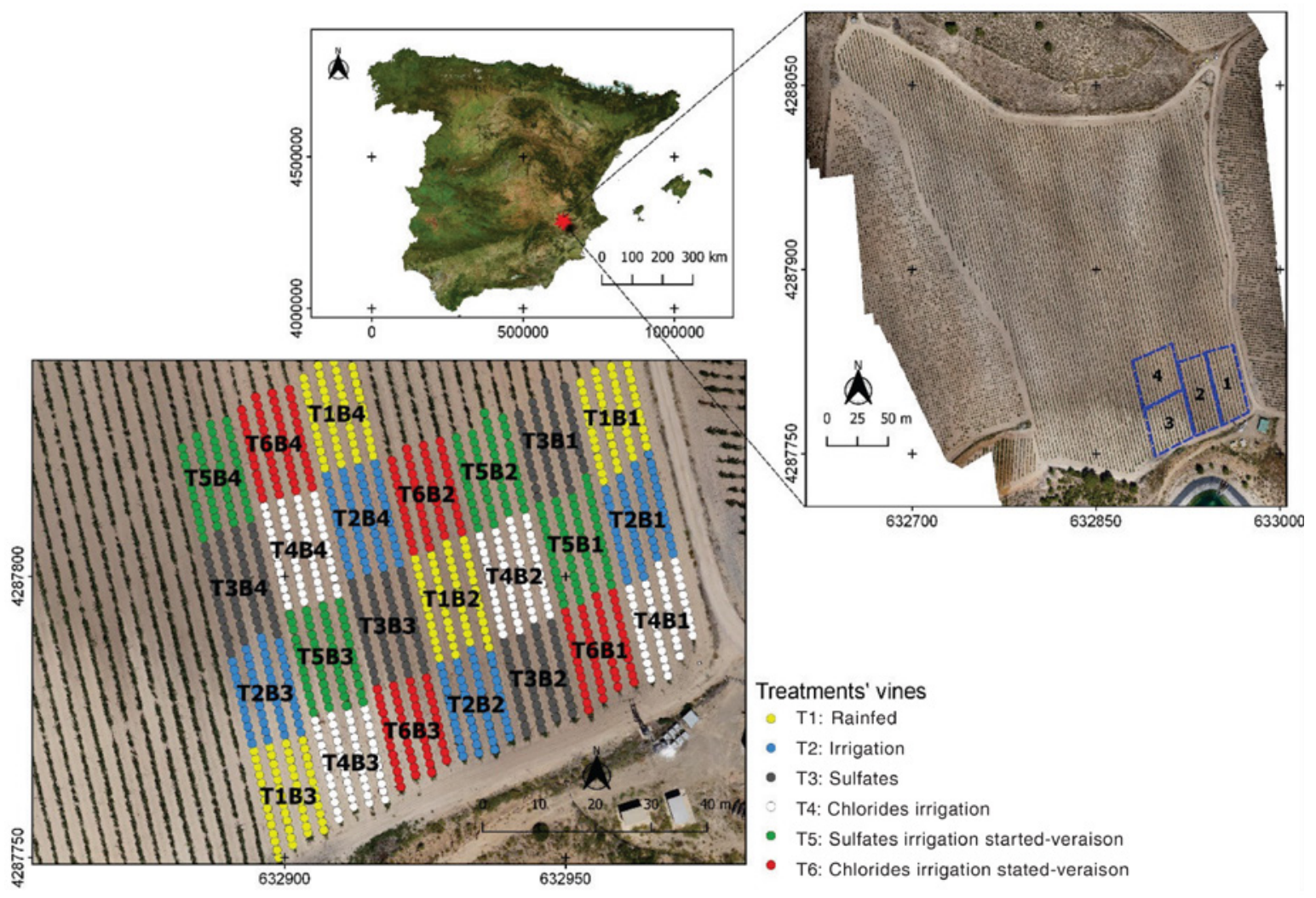

Figure 1 Location of the commercial vineyard cv. Monastrell in southeastern Spain and replicate plot field distribution where the study was performed during the 2018 and 2019 seasons. Each colored dot corresponds to a grapevine plant. 
limitations of the $S_{\psi}$ may occur when the number of days between two consecutive readings is high. It might have sudden and punctual changes in the water status that may not be noticed, but the $\mathrm{S}_{\psi}$ is the result of the crop water "history," as well as the canopy spectral response. It represents the accumulated water status of the vineyard from the beginning of the cycle until the measurement is taken. Therefore, the main objective of this manuscript is to relate the canopy spectral response with the $S_{\psi}$.

$$
S_{\varphi}=\left|\sum_{i=0}^{i=t}\left(\bar{\psi}_{i, i+1}-c\right) n\right|
$$

Eq. 1

Aerial imagery acquisition and processing. High-resolution multispectral ( $8 \mathrm{~cm}$ ground sample distance; GSD) and RGB ( $2 \mathrm{~cm}$ GSD) images were collected on the same days that $\Psi_{\text {stem }}$ was determined (Table 1). The UAV used was a quadcopter md4-1000 (Microdrones, Inc.) mounted with a multispectral Sequoia sensor (Parrot Drone SAS) and an RGB SONY ILCE-5100 digital camera (Sony Corporation). The multispectral Sequoia sensor measured four bands: green $(550 \mathrm{~nm}$ with a $40 \mathrm{~nm}$ bandpass filter $[\mathrm{BPF}])$, red $(660 \mathrm{~nm}$, BPF $40 \mathrm{~nm})$, red edge (735 nm, BPF $10 \mathrm{~nm})$, and NIR (790 nm, BPF $40 \mathrm{~nm})$. The sensor has a $4.8 \times 3.6 \mathrm{~mm}$ charge-coupled device and a pixel size of $3.75 \times 3.75 \mu \mathrm{m}$. The resolution of the image was $1280 \times 960$ (columns and rows, respectively) with a focal length of $3.98 \mathrm{~mm}$. The sensor of the SONY ILCE-5100 camera was a complementary metal oxide semiconductor (CMOS) Exmor type APS-C $(23.5 \times 15.6 \mathrm{~mm})$ with a pixel size of $4 \times 4 \mu \mathrm{m}$. The image size was $6000 \times 4000$ (columns and rows) and its focal length was $20 \mathrm{~mm}$. Flights were always performed near solar noon at a height of $80 \mathrm{~m}$ aboveground. Eight targets were uniformly distributed within the flying area for geo-referencing and sensor geometric cali- bration. The positions of the target centroids were determined using the Leica Global Positioning System (GPS) 1200 (Leica Geosystems AG) linked to a global navigation satellite system (GNSS) permanent reference station. The estimated accuracy of the GNSS real-time kinematic was $0.01 \mathrm{~m}$ in planimetry and $0.015 \mathrm{~m}$ in altimetry.

Images were automatically acquired following a flight plan computed using the Microdrones Photogrammetric Flight Planning software (Hernandez-Lopez et al. 2013). Before each flight, radiometric calibration was performed using the Aircalib calibration panel (Airinov) for the multispectral sensor. Blurred images were automatically detected and eliminated (Ribeiro-Gomes et al. 2016). Geomatic products (i.e., orthoimage, digital surface model, and point cloud) were obtained using the Agisoft Metashape Professional version 1.6.1 software (Agisoft, LLC).

Segmentation of well-illuminated vegetation in the orthoimages was performed using a modified version of the leaf area index calculation (LAIC) computer vision software (Córcoles et al. 2013) named GEO-LAIC. The GEO-LAIC was used for RGB imagery treatment and the MS-GEO-LAIC for multispectral imagery. This software also made it possible to determine the GCC (Figure 2). The GCC was computed for each vine according to the methodology proposed by Ballesteros et al. (2014). The software used for the extraction of geomatic information for each vine was QGis version 3.4.1 software (QGIS Development Team, 2019, QGIS Geographic Information System. Open Source Geospatial Foundation Project, https://qgis.org).

Calculation of VIs. Sensitivity of salt treatments on canopy spectral reflectance was previously assessed. There were no significant differences for any seasons and sampling events. Therefore, relationships between water stress integral and considered VIs were studied for all treatments together.

Table 1 Dates of stem water potential measurements and flights, calculated growing degree days (GDD), and accumulated applied water by rainfall and irrigation in the studied vineyard cv. Monastrell located in southeastern Spain in the 2018 and 2019 seasons. DOY, day of year.

\begin{tabular}{|c|c|c|c|c|c|}
\hline \multirow[b]{2}{*}{ Sampling date } & \multirow[b]{2}{*}{ DOY } & \multirow{2}{*}{$\begin{array}{c}\text { Growth stage } \\
\text { (Baggiolini scale }{ }^{a} \text { ) }\end{array}$} & \multirow[b]{2}{*}{ GDD } & \multicolumn{2}{|c|}{ Applied water (mm) } \\
\hline & & & & Rainfall & Irrigation \\
\hline \multicolumn{6}{|l|}{ Season 2018} \\
\hline 15 June & 166 & $\mathrm{H}-\mathrm{I}$ : flowering & 396 & 264 & 0 \\
\hline 2 July & 183 & $\mathrm{~J}$ : fruit set & 614 & 288 & 4 \\
\hline 27 July & 208 & L: closed bunch & 989 & 288 & 44 \\
\hline 14 Aug & 226 & M: beginning veraison & 1282 & 291 & 55 \\
\hline 23 Aug & 235 & M: veraison & 1394 & 307 & 70 \\
\hline 19 Sept & 262 & $\mathrm{~N}$ : berry ripening & 1720 & 337 & 99 \\
\hline \multicolumn{6}{|l|}{ Season 2019} \\
\hline 19 June & 170 & $\mathrm{~J}$ : beginning fruit set & 453 & 233 & 0 \\
\hline 4 July & 185 & $\mathrm{~J}$ : ended fruit set & 665 & 233 & 0 \\
\hline 16 July & 197 & $\mathrm{~K}$ : berry pea size & 849 & 240 & 0 \\
\hline 29 July & 210 & L: closed bunch & 1043 & 240 & 15 \\
\hline 14 Aug & 226 & M: veraison & 1289 & 240 & 19 \\
\hline 28 Aug & 240 & $\mathrm{~N}$ : beginning berry ripening & 1468 & 259 & 40 \\
\hline 18 Sept & 261 & $\mathrm{~N}$ : berry ripening & 1681 & 428 & 56 \\
\hline
\end{tabular}

\footnotetext{
aBaggiolini 1952.
} 
Different VIs were calculated from visible and NIR spectra measured in the RGB and multispectral orthoimages with segmented vegetation. The high resolution images allowed for calculation of a VI for each vine. Band values were computed as the mean of pixel values within its delimited vegetation area with QGis version 3.4.1 software (QGIS Development Team, 2019, QGIS Geographic Information System. Open Source Geospatial Foundation Project, https://qgis.org). Nevertheless, the average of grapevine bands within its replicate plot was band value of each replicate plot of the study because, in the data analysis of this study, average values for each replicate plot not at the grapevine level were used.

Statistical analysis. Pearson's correlation coefficient (r) was calculated for the multispectral and RGB VIs listed in Tables 2 and 3 . VIs that were highly correlated $(r \geq 0.95)$ were not considered. Pearson's correlation analysis was determined between the different VIs and GCC (as predictors) and $S_{\psi}$ throughout the entire growth cycle for the 2018 and

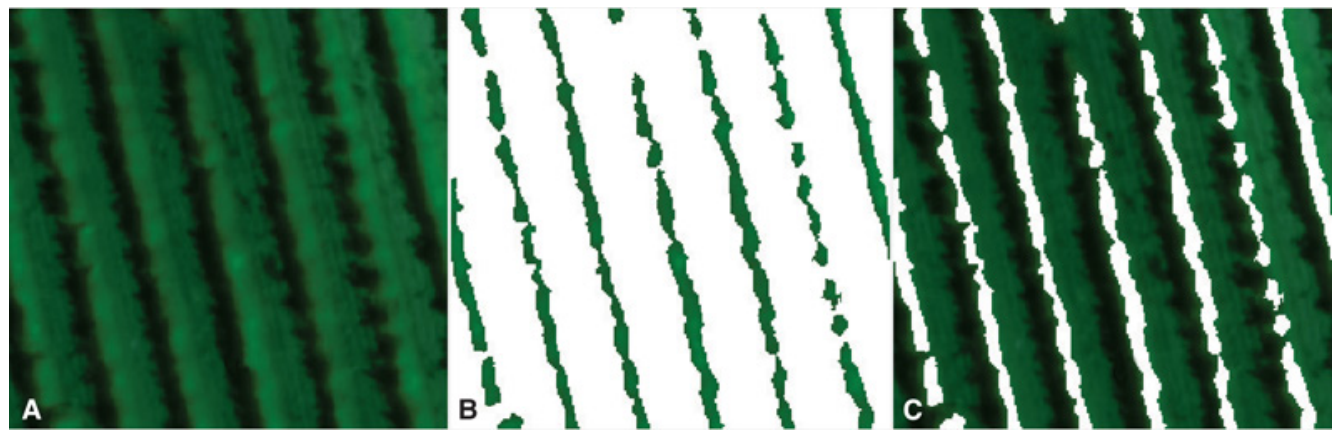

Figure 2 Three resulting images from well-illuminated vegetation segmentation with the computer software MS-GEO-LAIC, used for segmenting multispectral images: (A) the selected portion of the image; (B) the values of the pixels corresponding with the selected clusters; and (C) the values of the pixels corresponding to the unselected clusters.

Table 2 Multispectral vegetation indices (VIs) used in the present study calculated using the Parrot Sequoia sensor's set of bands. These VIs were calculated for vineyard cv. Monastrell located in southeastern Spain in 2018 and 2019 seasons.

\begin{tabular}{|c|c|c|c|}
\hline & Index & Equation & References \\
\hline GI & Greenness Index & $R_{550} / R_{670}$ & (Zarco-Tejada et al. 2005) \\
\hline GNDVI & $\begin{array}{l}\text { Green Normalized Difference Vegetation } \\
\text { Index }\end{array}$ & $\frac{R_{800}-R_{550}}{R_{800}+R_{550}}$ & (Gitelson and Merzlyak 1998) \\
\hline MCARI & $\begin{array}{l}\text { Modified Chlorophyll Absorption in } \\
\text { Reflectance Index }\end{array}$ & {$\left[\left(R_{700}-R_{670}\right)-0.2 *\left(R_{700}-R_{550}\right)\right] *\left(\frac{R_{700}}{R_{670}}\right)$} & (Daughtry et al. 2000) \\
\hline MCARI1 & $\begin{array}{l}\text { Modified Chlorophyll Absorption in } \\
\text { Reflectance Index } 1\end{array}$ & $1.2 *\left[2.5 *\left(R_{800}-R_{670}\right)-1.3 *\left(R_{800}-R_{550}\right)\right]$ & (Haboudane et al. 2004) \\
\hline \multirow[t]{2}{*}{ MCARI2 } & \multirow[t]{2}{*}{$\begin{array}{l}\text { Modified Chlorophyll Absorption in } \\
\text { Reflectance Index } 2\end{array}$} & $1.2 *\left[2.5 *\left(R_{800}-R_{670}\right)-1.3 *\left(R_{800}-R_{550}\right)\right]$ & \multirow[t]{2}{*}{ (Haboudane et al. 2004) } \\
\hline & & $\sqrt{\left(2 * R_{800}+1\right)^{2}-6 *\left(R_{800}-5 * R_{670}\right)-0.5}$ & \\
\hline MSAVI & Improved Soil-Adjusted Vegetation Index & $\frac{\left(2 * R_{800}+1-\sqrt{\left.\left(2 * R_{800}+1\right)^{2}-8 *\left(R_{800}-R_{670}\right)\right)}\right.}{2}$ & (Qi et al. 1994) \\
\hline MSR & Modified Simple Ratio & $\frac{\frac{R_{800}}{R_{670}}-1}{\sqrt{\frac{R_{800}}{R_{670}}+1}}$ & (Chen 1996) \\
\hline MTVI3 & Modified Triangular Vegetation Index & $1.2 *\left[1.2 *\left(R_{800}-R_{550}\right)-2.5 *\left(R_{670}-R_{550}\right)\right]$ & $\begin{array}{l}\text { (Rodríguez-Pérez et al. } \\
\text { 2007) }\end{array}$ \\
\hline NDVI & Normalized Difference Vegetation Index & $\frac{R_{800}-R_{670}}{R_{800}+R_{670}}$ & (Rouse et al. 1973) \\
\hline $\begin{array}{l}\text { TCARI/ } \\
\text { OSAVI }\end{array}$ & $\begin{array}{l}\text { Transformed Chlorophyll Absorption } \\
\text { in Reflectance Index/Optimized Soil- } \\
\text { Adjusted Vegetation Index }\end{array}$ & $\frac{3 *\left[\left(R_{700}-R_{670}\right)-0.2 *\left(R_{700}-R_{550}\right) *\left(R_{700} / R_{670}\right)\right]}{(1+0.16) *\left(R_{800}-R_{670}\right) /\left(R_{800}+R_{670}+0.16\right)}$ & (Haboudane et al. 2002) \\
\hline$\overline{\mathrm{SRI}}$ & Simple Ratio Index & $\frac{R_{800}}{R_{550}}$ & (Jordan 1969) \\
\hline RDVI & Renormalized Difference Vegetation Index & $\frac{R_{800}-R_{670}}{\sqrt{R_{800}+R_{670}}}$ & (Roujean and Breon 1995) \\
\hline
\end{tabular}


2019 seasons. Simple linear regression models were assessed using as predictors multispectral and RGB VIs with $\mathrm{r}$ values of $>0.5$ in the last dates for 2018 and 2019. The coefficient of determination $\left(R^{2}\right)$ and the relative error (RE) were used to assess the performance of the obtained models for each irrigation season. The regression trend line between measured $\mathrm{S}_{\psi}$ and simulated $\mathrm{S}_{\psi}$, using the VI with the best performance as predictor, was also shown to study the trend of the calibrated model to overestimate or underestimate $S_{\psi}$ values. Validation was performed in the 2019 data to test the obtained models in 2018; for this, $\mathrm{R}^{2}, \mathrm{RE}$, and the regression line between measured $S_{\psi}$ and simulated $S_{\psi}$ were used to assess the performance.

\section{Results}

Accumulated water stress obtained under different treatments. Analyzing the computed $\mathrm{S}_{\psi}$ for each sampling date in the 2018 season (Figure 3), differences between treatments were not significant until 14 Aug, even though the first irrigation event was on 2 July for treatments T2 through T4. Differences between T1 (rainfed grapevines) and the rest of the treatments were significant on 14 Aug (at the beginning of veraison), at $1282 \mathrm{GDD}$, and when the total applied water was $291 \mathrm{~mm}$ from rainfall and $55 \mathrm{~mm}$ from irrigation. As expected, for that date, $\mathrm{T} 1$ showed the highest water stress, with an average $S_{\psi}$ of $28.9 \mathrm{MPa} \times$ days. The lowest $\mathrm{S}_{\psi}$ average value was $19 \mathrm{MPa} \times$ days for T2 (irrigated with standardquality water). The rest of the treatments showed mean values close to $23 \mathrm{MPa} \times$ days, in the case of T3 and T4 (irrigated with added sulfates and $\mathrm{NaCl}$, respectively), and close to 26 $\mathrm{MPa} \times$ days for T5 and T6 (irrigated with added sulfates and $\mathrm{NaCl}$ respectively, with watering starting at veraison). In addition, significant differences appeared between T2, T5, and
T6, due to the later start of irrigation events. No differences were observed between T2, T3, and T4. Therefore, the results indicate that there were no differences resulting from the two salt types (i.e., T3 versus $\mathrm{T} 4$ and $\mathrm{T} 5$ versus $\mathrm{T} 6$ ). In the last two sampling dates, the treatments' $S_{\psi}$ values had the same trend as on 14 Aug. Differences between T1 and the rest of the treatments were significant on 19 Sept (at berry ripening) at 1720 GDD and when the total applied water reached $337 \mathrm{~mm}$ from precipitation and $99 \mathrm{~mm}$ from irrigation. T1 showed the highest water stress, with an average $\mathrm{S}_{\psi}$ of $64.3 \mathrm{MPa} \times$ days, while the lowest $S_{\psi}$ average value was $35.3 \mathrm{MPa} \times$ days for T2; the rest of treatments showed mean values close to $44 \mathrm{MPa} \times$ days for $\mathrm{T} 3$ and $\mathrm{T} 4$, and close to $50 \mathrm{MPa} \times$ days for $\mathrm{T} 5$ and $\mathrm{T} 6$.

Analyzing the computed $\mathrm{S}_{\psi}$ for each sampling date of the 2019 season (Figure 4), differences between treatments were not significant until 29 July. In the previous sampling dates, the irrigation treatments had not started yet. Differences between T1 (rainfed) and T2 (irrigated with standard-quality water) were observed on 29 July (at phenological phase of closed bunch), at $1043 \mathrm{GDD}$, and when the cumulative irrigation water was $15 \mathrm{~mm}$. For that day, T1 showed an average $\mathrm{S}_{\psi}$ value of $12.3 \mathrm{MPa} \times$ days and T2 of $7.4 \mathrm{MPa} \times$ days. Differences between $\mathrm{T} 1, \mathrm{~T} 2$, and T4 with average $\mathrm{S}_{\psi}$ values of 21.9, 12.9 , and $18.9 \mathrm{MPa} \times$ days were detected, respectively, on 14 Aug (at veraison) at 1289 GDD and with total applied water of $240 \mathrm{~mm}$ from rainfall and $19 \mathrm{~mm}$ from irrigation. Differences between $\mathrm{T} 1$ and the other treatments were the most significant, with an average $\mathrm{S}_{\psi}$ value of $35.5 \mathrm{MPa} \times$ days for $\mathrm{T} 1$ and lowest mean value of $19.1 \mathrm{MPa} \times$ days for T2 on 28 Aug (at beginning of berry ripening) at 1468 GDD and with total applied water of $259 \mathrm{~mm}$ from rainfall and $40 \mathrm{~mm}$ from irrigation. The same trend appeared in the last sampling date, with the highest average value for $\mathrm{T} 1(47.6 \mathrm{MPa} \times$ days) and

Table 3 Red, green, blue (RGB) vegetation indices (VIs) used in the present study calculated using the SONY-ILCE 5100 sensor's set of bands. These VIs were calculated for vineyard cv. Monastrell located in southeastern Spain in 2018 and 2019 seasons.

\begin{tabular}{llcl}
\hline & Index & Equation & References \\
\hline$\rho$ & Normalized red & $\frac{R}{R+G+B}$ & (Saberioon et al. 2014) \\
\hline$\gamma$ & Normalized green & $\frac{G}{R+G+B}$ & (Saberioon et al. 2014) \\
\hline NGRDI & Normalized blue & $\frac{B}{R+G+B}$ & (Saberioon et al. 2014) \\
\hline Ikaw & Kormalized Green Red Difference Index & (Gitelson et al. 2002) \\
\hline ExR & Excess Red Vegetation Index & $\frac{\rho-\beta}{\rho+\beta}$ & (Kawashima and Nakatani 1998) \\
\hline ExB & Excess Blue Vegetation Index & $1.4 * \rho-\gamma$ & (Mao et al. 2003) \\
\hline ExG & Excess Green Vegetation Index & $1.4 * \beta-\gamma$ & (Mao et al. 2003) \\
\hline ExGR & Excess Green minus Excess Red Index & $2 * \gamma-\rho-\beta$ & (Mao et al. 2003) \\
\hline RGRI & Red Green Ratio Index & $E x G-E x R$ & (Mao et al. 2003) \\
\hline GLI & Green Leaf Index & $\frac{\rho}{\gamma}$ & (Saberioon et al. 2014) \\
\hline VARI & Visible Atmospherically Resistance Index & $\frac{2 * \gamma-\rho-\beta}{2 * \gamma+\rho+\beta}$ & $\frac{\gamma-\rho}{\gamma+\rho-\beta}$ \\
\hline
\end{tabular}


the lowest mean value for T2 $(23.6 \mathrm{MPa} \times$ days). Significant differences between T2, T3, and T4 (added salts) were not observed. Therefore, it was shown that irrigation with added salts did not influence the grapevine water status, as was previously observed in 2018.

Correlation of the VIs and analysis of the VIs and GCC with $\mathbf{S}_{\psi}$. Analysis of Pearson's correlation between the different multispectral VIs for 2018 and 2019 seasons showed that MCARI1, MCARI2, MSAVI, MTVI3, MSR, and SRI had correlation coefficients higher than 0.95 , revealing a high level of multicollinearity. Therefore, the multispectral VIs considered were NDVI, GI, GNDVI, MCARI, RDVI, and TCARI/ OSAVI. See Table 2 for the definitions of these abbreviations.

Analysis of Pearson's correlation between the different RGB VIs for 2018 and 2019 seasons showed that $\gamma$, NGRDI, Ikaw, ExR, ExB, ExG, ExGR, and RGRI had correlation
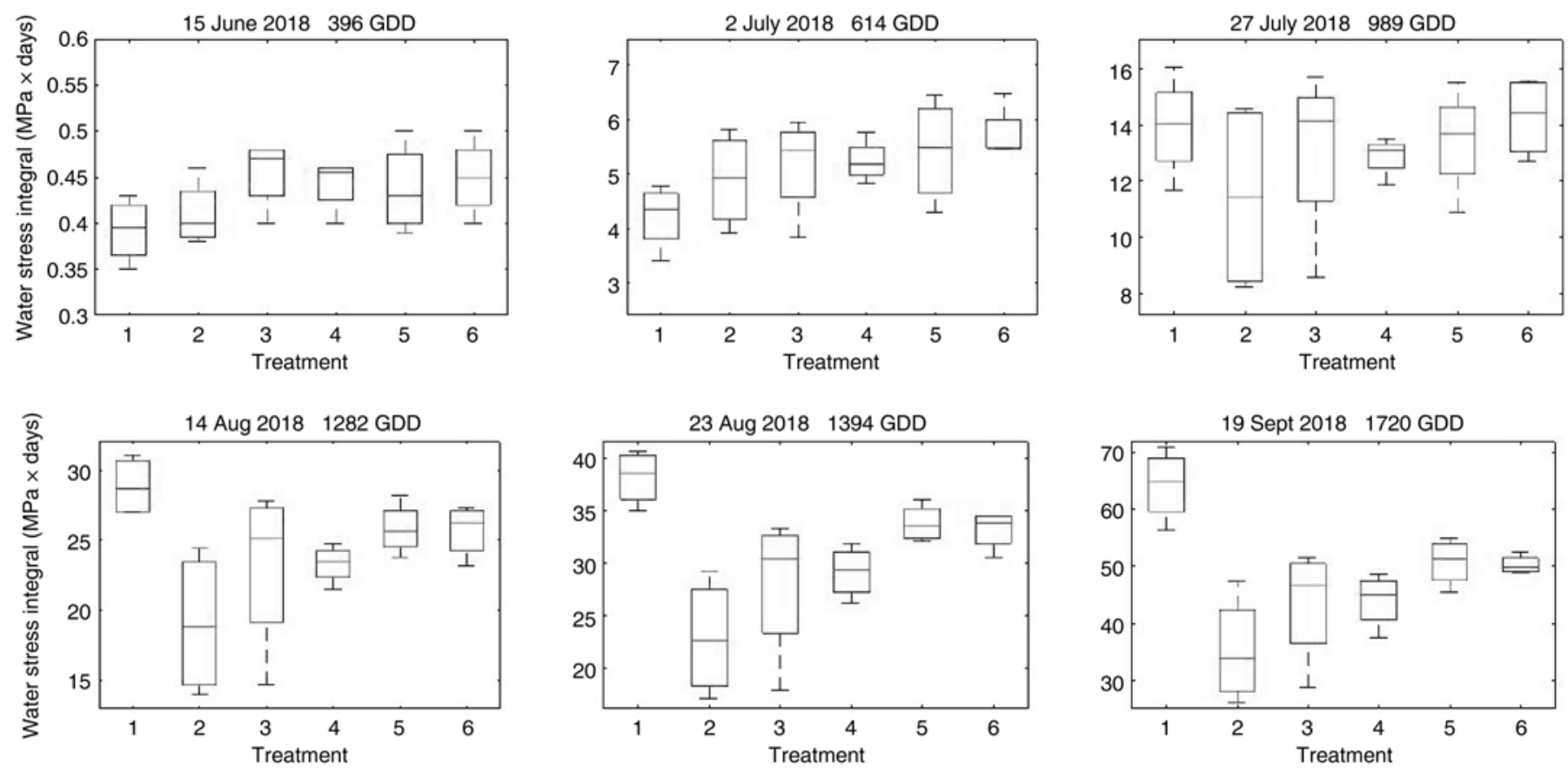

Figure 3 Water stress integral (MPa $\times$ days) of the studied vineyard for different treatments of experimental design at different sampling dates in the 2018 season. GDD, growing degree days.
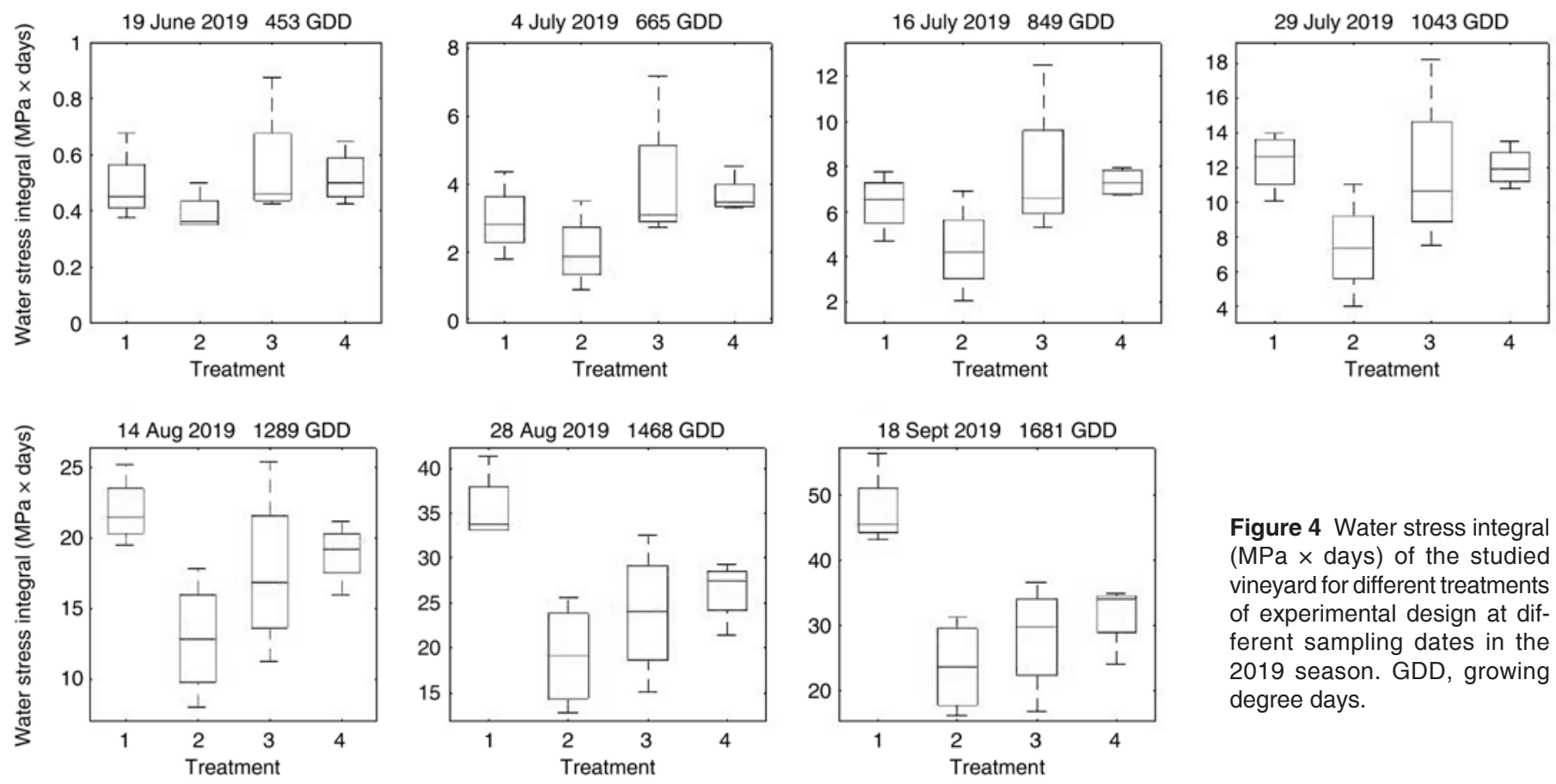

Figure 4 Water stress integral $(\mathrm{MPa} \times$ days) of the studied vineyard for different treatments of experimental design at different sampling dates in the 2019 season. GDD, growing degree days. 
coefficients higher than 0.95 , revealing a high level of multicollinearity. Therefore, the RGB VIs considered were $\rho$, $\beta$, GLI, and VARI. See Table 3 for the definitions of these abbreviations and variables.

For selected VIs, Table 4 shows $r$ values for the relationships between the most significant multispectral and RGB VIs (with $\mathrm{r}$ values $>0.5$ in some dates) with $\mathrm{S}_{\psi}$ in the 2018 season. Generally, $r$ values were higher at the last sampling dates for both types of VIs. Moreover, $r$ values were higher for RGB VIs. The GCC, which is considered a geometric parameter and not a spectral VI, showed a good relationship with grapevine water stress. Therefore, canopy growth or grapevine vigor is highly influenced by the accumulated water stress. After Pearson's analysis, we studied simple linear regression models of the multispectral and RGB VIs with $r$ values $>0.5$ in the last three or two dates. In the case of multispectral VIs, we considered NDVI, GNDVI, and RDVI. For RGB VIs, we considered GLI, VARI, and the geometric parameter GCC.

Table 5 shows the $r$ values for the relationships between the most significant multispectral and RGB VIs (with $r$ values $>0.5$ in some dates) with $\mathrm{S}_{\psi}$ in the 2019 season. Generally, $\mathrm{r}$ values were higher in the last sampling dates for both types of VI, as occurred in 2018. Nevertheless, some multispectral VIs only showed $r$ values of $>0.5$ in the last sampling date (18 Sept 2019): NDVI, GNDVI, and TCARI/OSAVI. In the case of RGB VIs, as in 2018, GLI, VARI, and GCC had r values of $>0.5$ in the last three sampling dates (but lower than those in 2018); except for GCC, with a r value of 0.31 on 18 Sept. GLI also had $r$ values of $>0.5$ on 16 and 29 July.

Simple linear regression analysis. To determine a model to predict grapevine water status, simple linear regression analysis between the multispectral VIs NDVI, GNDVI, and RDVI and the RGB VIs GLI, VARI, and GCC and $\mathrm{S}_{\psi}$ was evaluated for each sampling date in 2018. Table 6 shows the statistical analysis for obtained RGB linear models in the 2018 season. The statistical analysis of multispectral VI predictors was not detailed because $\mathrm{R}^{2}$ values were lower than 0.5 . Therefore, multispectral VIs offered weak results. According to the $r$ values, the best fits were obtained in the last three sampling dates. The best fit considering RGB VIs as predictor variables was obtained for GLI $\left(\mathrm{R}^{2}=0.8\right.$ and $\mathrm{RE}$ $=8.75 \%$ ) as a predictor for the last date, $23 \mathrm{Aug}$, at veraison (at 1394 GDD) (Figure 5A). Generated models using VARI as predictor also had good fits for the last two dates, with $\mathrm{R}^{2}>0.5$ and $\mathrm{RE}>10 \%$. The generated model, including GCC as a predictor, showed a good fit with $\mathrm{R}^{2}>0.5$ and $\mathrm{RE}$ close to $10 \%$, for the last three dates and with the best fits on 27 July and 14 Aug with $\mathrm{R}^{2}=0.65$ and 0.67 , and $\mathrm{RE}=9.73$ and $10.22 \%$, respectively.

To determine a model to predict grapevine water status, simple linear regression analysis between the multispectral

Table 4 Pearson's correlation coefficients for the relationships between the most significant vegetation indices (VIs) with water stress integral (MPa $\times$ days) in the 2018 season for the studied vineyard cv. Monastrell located in southeastern Spain. RGB, red green blue; NDVI, normalized difference vegetation index; GNDVI, green normalized difference vegetation index; RDVI, renormalized difference vegetation index; GLI, green leaf index; VARI, visible atmospherically resistance index; GCC, green cover canopy.

\begin{tabular}{|c|c|c|c|c|c|c|}
\hline & \multicolumn{3}{|c|}{ Multispectral Vls } & \multicolumn{3}{|c|}{ RGB VIs } \\
\hline & NDVI & GNDVI & RDVI & GLI & VARI & GCC \\
\hline 15 June 2018 & -0.06 & -0.05 & -0.26 & 0.19 & 0.07 & -0.23 \\
\hline 2 July 2018 & & & & -0.19 & -0.16 & -0.43 \\
\hline 27 July 2018 & -0.27 & -0.26 & -0.17 & -0.32 & $-0.56^{a}$ & -0.81 \\
\hline 14 Aug 2018 & -0.62 & -0.66 & -0.67 & -0.70 & -0.75 & -0.82 \\
\hline 23 Aug 2018 & -0.65 & -0.67 & -0.66 & -0.89 & -0.85 & -0.85 \\
\hline 19 Sept 2018 & -0.64 & -0.70 & -0.59 & & & \\
\hline
\end{tabular}

aPearson's correlation coefficients $(r)$ shown in bold indicate the best-performing model on each sampling date with $r$ values of $>0.5$.

Table 5 Pearson's correlation coefficients for the relationships between the most significant vegetation indices (VIs) with water stress integral (MPa $\times$ days) in the 2019 season for the studied vineyard cv. Monastrell located in southeastern Spain. RGB, red green blue; NDVI, normalized difference vegetation index; GNDVI, green normalized difference vegetation index; TCARI/OSAVI, transformed chlorophyll absorption in reflectance index/optimized soil-adjusted vegetation index; GLI, green leaf index; VARI, visible atmospherically resistance index; GCC, green cover canopy.

\begin{tabular}{|c|c|c|c|c|c|c|}
\hline & \multicolumn{3}{|c|}{ Multispectral VIs } & \multicolumn{3}{|c|}{ RGB VIs } \\
\hline & NDVI & GNDVI & TCARI/OSAVI & GLI & VARI & GCC \\
\hline 19 June 2019 & $1.2 e-3$ & 0.11 & 0.09 & -0.24 & -0.22 & 0.08 \\
\hline 4 July 2019 & -0.28 & -0.01 & 0.11 & -0.41 & -0.35 & -0.37 \\
\hline 16 July 2019 & -0.37 & -0.3 & 0.35 & $-0.53^{a}$ & -0.39 & -0.4 \\
\hline 29 July 2019 & -0.32 & -0.26 & 0.32 & -0.58 & -0.38 & -0.34 \\
\hline 14 Aug 2019 & -0.44 & -0.34 & 0.35 & -0.5 & -0.67 & -0.53 \\
\hline 28 Aug 2019 & -0.35 & -0.4 & 0.63 & -0.77 & -0.75 & -0.57 \\
\hline 18 Sept 2019 & -0.51 & -0.64 & 0.68 & -0.48 & -0.73 & -0.31 \\
\hline
\end{tabular}

aPearson's correlation coefficients ( $r$ ) shown in bold indicate the best-performing model on each sampling date with $r$ values of $>0.5$. 
VIs NDVI, GNDVI, and TCARI/OSAVI and the RGB VIs GLI, VARI, and GCC and $S_{\psi}$ was evaluated for each sampling date in 2019. Table 6 shows the statistical analysis for obtained RGB linear models in the 2019 season. Despite the last sampling date, in the case of NDVI and GNDVI, or the last two dates, in the case of TCARI/OSAVI, showing the best fits, neither had $\mathrm{R}^{2}>0.5$, so no multispectral model was significant to predict $S_{\psi}$ (as in 2018); hence, the statistical analysis obtained using multispectral VIs as predictors is not shown. In the case of generated models with GCC as predictor, no date had $\mathrm{R}^{2}>0.5$. In the case of GLI, the model only showed $\mathrm{R}^{2}>0.5$ on 28 Aug at 1468 GDD (at the beginning of berry ripening). For generated models using VARI as a predictor, only the last two dates had good fit (with $\mathrm{R}^{2}>0.5$ ). In this year, the models did not fit as well as in 2018.

Validation process. To evaluate the model generated in 2018, it was applied to the data obtained in 2019. The best linear regression model of the calibration process in 2018 was GLI, with the best statistics on 23 Aug (1394 GDD), with $\mathrm{R}^{2}=0.8$ and $\mathrm{RE}=8.75 \%$. To validate this model, the calibration equation between GLI and measured $\mathrm{S}_{\psi}$ was applied to GLI on 28 Aug 2019 with 1468 GDD because it was similar in the GDD at 23 Aug 2018. The resulting statistical values were $\mathrm{R}^{2}=0.59$ and $\mathrm{RE}=33.82 \%$. The model underestimated the $S_{\psi}$ values when higher $S_{\psi}$ values were reached (Figure 5B). No multispectral models were validated because their results were not robust $\left(\mathrm{R}^{2}<0.5\right)$.

\section{Discussion}

In both years, differences between the treatments were not clearly observed until mid-August - around veraison — and were mostly found between irrigation regimes, while the ap- plication of salt water did not clearly affect grapevine water status. This confirms that the $\Psi_{\text {stem }}$ measurement is a good indicator for the watering regime imposed, as was recently analyzed in a meta-analysis study (Santesteban et al. 2019). On the other hand, the application of salt water did not affect plant water status, probably because the vineyard's sandy soil avoided the important accumulation of salts in the root zone. The leaf spectral response was also not affected by the water salinity levels. Thus, data from the different combinations of watering and salinity levels were pooled together when relating vine water status with spectral indices calculated. Studies determining salinity effects on leaf spectral indices are still scarce. Recently, it was found that in citrus trees, only after eight seasons of continuous application of salty water from treated wastewater could a differential response in canopy multispectral response be detected (Romero-Trigueros et al. 2017). Comparing the two seasons, the $S_{\psi}$ values were lower in 2019 than in 2018 because of the lowest $\Psi_{\text {stem }}$ values, computed in the last three sampling dates of 2019. During those growing seasons, irrigation and rainfall events were less frequent but with more intensity; this period was highlighted by having more than $35 \mathrm{~mm}$ from rainfall and irrigation registered prior to $28 \mathrm{Aug}$ or more than $100 \mathrm{~mm}$ from rainfall prior to $18 \mathrm{Sept}$. A possible reason that the strongest relationships between water stress and the multispectral and RGB VIs occurred on the last measurement dates is that $S_{\psi}$ considers accumulated water stress throughout the growing cycle, which probably affected the structural and pigment content of the leaves and, therefore, the spectral response; that is, the source of VIs.

In this study, multispectral and RGB VIs were considered predictors of $\mathrm{S}_{\psi}$. The VIs having the strongest relationship

\begin{tabular}{|c|c|c|c|c|c|c|c|c|c|c|c|c|}
\hline \multirow{2}{*}{$\begin{array}{l}\text { RGB VIs and GCC } \\
\text { in } 2018 \text { season }\end{array}$} & \multicolumn{4}{|c|}{ GLI } & \multicolumn{4}{|c|}{ VARI } & \multicolumn{4}{|c|}{ GCC } \\
\hline & $\mathbf{R}^{2 \mathrm{~b}}$ & RE (\%) & $\mathbf{a}$ & b & $\mathbf{R}^{2}$ & RE (\%) & a & b & $\mathbf{R}^{2}$ & RE (\%) & $\mathbf{a}$ & b \\
\hline 15 June 2018 & 0.04 & 9.14 & 0.83 & 0.34 & $3.5 e-3$ & 9.29 & 0.27 & 0.42 & 0.05 & 9.06 & $-5.9 e-3$ & 0.48 \\
\hline 2 July 2018 & 0.04 & 15.27 & -9.25 & 6.62 & 0.03 & 15.35 & -5.1 & 5.55 & 0.18 & 14.06 & -0.11 & 6.57 \\
\hline 27 July 2018 & 0.11 & 15.65 & -83 & 23.9 & 0.32 & 13.66 & -115 & 24.56 & $0.65^{c}$ & 9.73 & -0.74 & 22.68 \\
\hline 14 Aug 2018 & 0.48 & 12.79 & -273.75 & 49.94 & 0.56 & 11.78 & -209.08 & 37.05 & 0.67 & 10.22 & -1.49 & 45.06 \\
\hline 23 Aug 2018 & 0.8 & 8.75 & -479.01 & 74.42 & 0.72 & 10.35 & -346.75 & 46.1 & 0.73 & 10.19 & -1.78 & 57.81 \\
\hline \multirow{2}{*}{$\begin{array}{l}\text { RGB VIs and GCC } \\
\text { in } 2019 \text { season }\end{array}$} & \multicolumn{4}{|c|}{ GLI } & \multicolumn{4}{|c|}{ VARI } & \multicolumn{4}{|c|}{ GCC } \\
\hline & $\mathbf{R}^{2}$ & RE (\%) & a & b & $\mathbf{R}^{2}$ & RE (\%) & a & b & $\mathbf{R}^{2}$ & RE (\%) & a & b \\
\hline 19 June 2019 & 0.06 & 26.67 & -4.81 & 1.04 & 0.05 & 26.74 & -3.03 & 0.64 & $6.7 e-3$ & 27.37 & $6.8 \mathrm{e}-3$ & 0.43 \\
\hline 4 July 2019 & 0.17 & 40.03 & -57.03 & 12.02 & 0.13 & 41 & -47.81 & 7.69 & 0.13 & 40.75 & -0.17 & 5.45 \\
\hline 16 July 2019 & 0.29 & 28.76 & -116.12 & 21.01 & 0.15 & 31.43 & -46.51 & 10.17 & 0.16 & 31.31 & -0.32 & 10.2 \\
\hline 29 July 2019 & 0.32 & 24.38 & -252.7 & 37.58 & 0.15 & 27.33 & -84.73 & 15.48 & 0.11 & 27.87 & -0.39 & 15.26 \\
\hline 14 Aug 2019 & 0.25 & 22.85 & -433.9 & 52.23 & 0.46 & 19.43 & -297.98 & 27.67 & 0.28 & 22.41 & -0.79 & 30.71 \\
\hline 28 Aug 2019 & 0.59 & 18.32 & -590.43 & 94.73 & 0.55 & 19.24 & -434.1 & 47.11 & 0.33 & 23.53 & -2.52 & 53.22 \\
\hline 18 Sept 2019 & 0.23 & 28.88 & -505.38 & 81.4 & 0.55 & 22.02 & -986.13 & 49.9 & 0.09 & 31.22 & -1.36 & 47.96 \\
\hline
\end{tabular}

aStatistics of generated simple linear regression models using multispectral VIs as predictors are not shown because all analyzed models including multispectral VIs as predictor reached $\mathrm{R}^{2}$ values of $<0.5$. Therefore, multispectral VIs offered weak results in 2018 and 2019.

${ }^{b} R^{2}$ : coefficient of determination; RE: relative error; $a$ and $b$ : coefficients of the generated model's equation $\left(S_{\psi}=a x+b\right)$.

'Statistical values shown in bold indicate the best-performing model on each sampling date. 
with $\mathrm{S}_{\psi}$ were NDVI, GNDVI, RDVI, TCARI/OSAVI, GLI, VARI, and the geometric parameter GCC, where the best results were obtained in the visible domain (i.e., with GLI, VARI, and GCC), with the GLI performance at the last sampling date of 2018 being notable. Few authors have used RGB VIs to predict water status (Möller et al. 2007, RodríguezPérez et al. 2007, Rossini et al. 2013, Zarco-Tejada et al. 2013, Pôças et al. 2015) because the visible part of the spectrum is characterized by low reflectance due to the strong absorption of foliar pigments. Möller et al. (2007) used thermal and visible images to develop models for estimating $\Psi_{\text {stem }}$. Nevertheless, RGB VIs were not computed and RGB imagery were used only as supporting data. Rodríguez-Pérez et al. (2007), Zarco-Tejada et al. (2013), and Rossini et al. (2013) used the
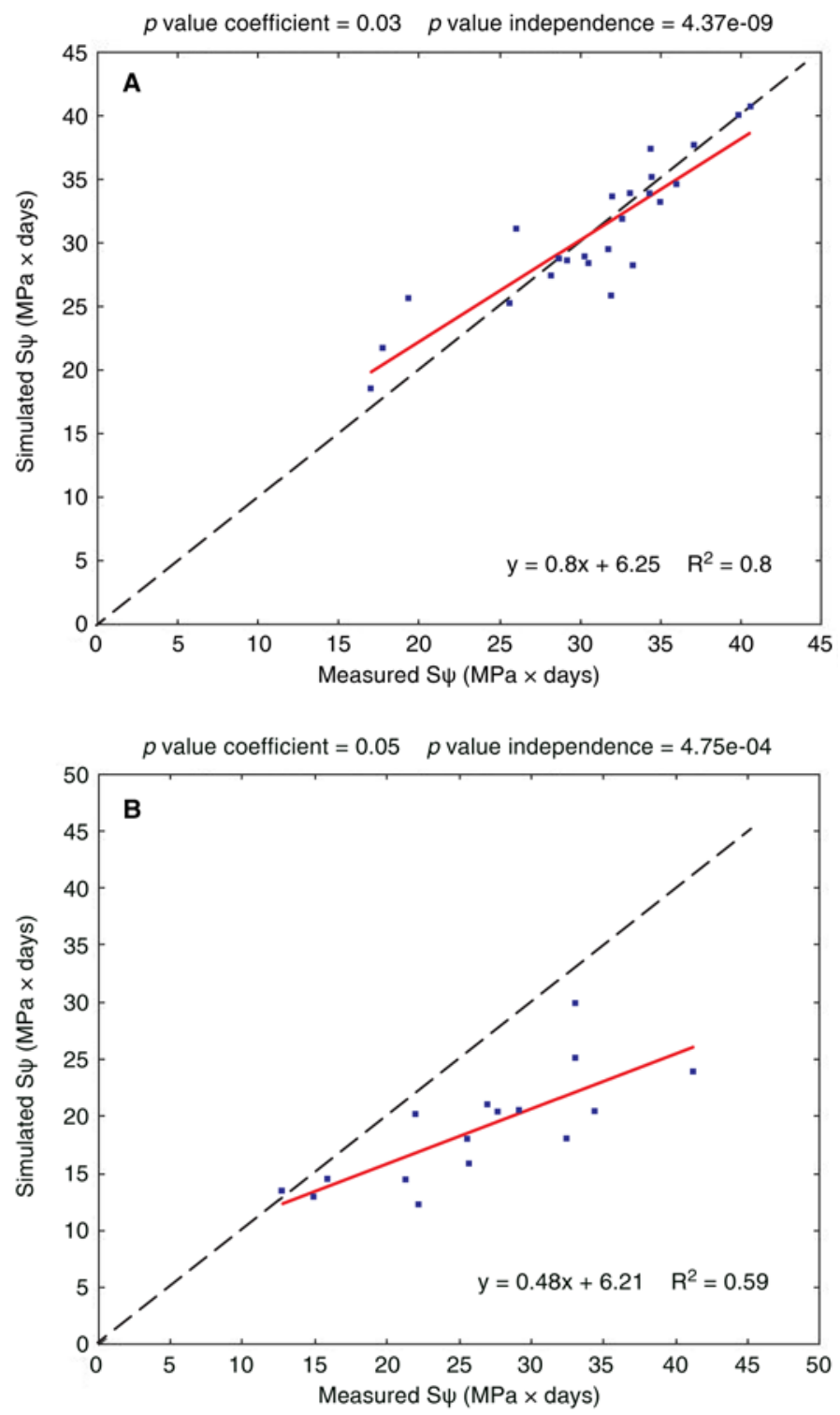

Figure 5 Regression line of: (A) measured water stress integral ( $\mathrm{S} \psi$ ) and simulated $\mathrm{S} \psi$ with the calibrated model that used as predictor green leaf index (GLI) data for 23 Aug 2018 with 1394 growing degree days (GDD), and $(B)$ the validation process using the equation of the calibrated model with GLI data of 28 Aug 2019 with 1468 GDD, similar to the calibrated model (1394 GDD). photochemical reflectance index (PRI), suggesting its use as a good indicator for water stress monitoring. In this study, PRI was not computed because it requires the 530 and 550 wavelengths of the visible region electromagnetic spectrum and the RGB sensor used only provides wavelengths corresponding to red $(670 \mathrm{~nm})$, green $(550 \mathrm{~nm})$, and blue $(470$ $\mathrm{nm})$. Pôças et al. (2015) also used hyperspectral reflectance indices to predict vineyard $\Psi_{\mathrm{pd}}$. Their study showed $\mathrm{R}^{2}$ values ranging from 0.37 to 0.58 , having better fit when using VARI $\left(\mathrm{R}^{2}=0.58\right)$. In this study, the best fit of VARI was with 2018's last sampling event for calibration $\left(\mathrm{R}^{2}=0.72\right)$.

Several studies have used multispectral and thermal VIs to determine water status. Baluja et al. (2012) reported that the highest correlations were obtained for NDVI, MSR, SRI, GNDVI, and TCARI/OSAVI predictors, with $\mathrm{R}^{2}$ values ranging between 0.58 (GNDVI) and 0.68 (NDVI). In the present study, for both calibration years (2018 and 2019), $\mathrm{R}^{2}$ values using NDVI and GNDVI as predictors were less accurate $(0.42$ and 0.49 , respectively) for the last sampling date of 2018 (19 Sept with 1720 GDD). In 2019, the $\mathrm{R}^{2}$ values of models generated using NDVI, GNDVI, and TCARI/OSAVI were 0.26 , 0.41 , and 0.46 , respectively, for the last sampling date (18 Sept with 1681 GDD). Poblete et al. (2017) obtained $\mathrm{R}^{2}$ values for NDVI and GNDVI of 0.35 and 0.31, respectively; lower than the obtained values in this study with the 2018 calibration. Romero et al. (2018) obtained $\mathrm{R}^{2}$ values for NDVI ranging between 0.12 and 0.29 for three sampling dates; lower values than those obtained in the 2018 calibration in this study, and similar to the values obtained in the 2019 calibration. These multispectral VIs can only indirectly detect water status because they were developed to represent different physiological variables that can change according to different levels of water status (Poblete et al. 2017). In this context, NDVI has been reported to be a good indicator of vegetative vigor, yield, and plant water status (Acevedo-Opazo et al. 2008b), while GNDVI has been reported as a better form to detect chlorophyll pigment concentration, which is modified under stress conditions (Gitelson and Merzlyak 1998).

In the studies carried out by Baluja et al. (2012), Poblete et al. (2017), and Romero et al. (2018), multispectral VIs were related with $\Psi_{\text {stem }}$ values, which characterizes the grapevine water status at the moment of determination. Nevertheless, unlike the previous works, the computed VIs in this study were related to $S_{\psi}$, which integrates the measured $\Psi_{\text {stem }}$ at each sampling date to obtain an accumulated value of water stress, which in turn reflects the effect of water deficit duration and intensity. In the case where instantaneous water stress determination is required, thermal imagery is probably more appropriate; although, the associated sensor cost and the difficulty of obtaining an accurate geomatic product increase the cost and decrease the applicability of the methodology (Ribeiro-Gomes et al. 2016). Nevertheless, using just RGB products can offer a good solution for determining accumulated water stress, which is a variable used in vineyard water management, particularly for characterizing vineyard zones that may have suffered from different degrees of water stress. Determination of the actual water status by determining $\Psi_{\text {stem }}$ 
is more useful for irrigation scheduling and modulating the irrigation regime, according to the instantaneous water stress suffered by the grapevines.

In the current study, we compared VIs computed from multispectral bands of the Parrot Sequoia and RGB bands from a conventional camera, the Sony ILCE 5100. RGB VIs integrating only information in the visible domain showed better correlations with $\mathrm{S}_{\psi}$. Moreover, the good performance of these visible VIs was due to the higher spatial resolution, which clearly compensates for the lower reflectance in the visible region compared with that in NIR and red edge. The green band is characterized by absorption of radiation by the anthocyanins, which are water-soluble pigments associated with the resistance of plants to stresses such as water deficits (Viña and Gitelson 2011). Blue-band wavelengths refer to a strong absorption by carotenes and xanthophylls which, along with chlorophyll, are used as indicators of physiological states and plant adaptation to stress (Gitelson 2011). Thus, the capability of very-high resolution products in the visible region of the spectrum allows for generating accurate data from the green band, avoiding the need to use multispectral sensors. According to the above results, using RGB VIs to predict $S_{\psi}$, instead of traditional multispectral VIs: 1) could reduce costs because RGB cameras are much cheaper than multispectral cameras; 2) could improve the generation of accurate orthoimages because structure-from-motion software is designed to work with RGB images; 3) sun glint and hotspot effects are less pronounced in RGB images than in multispectral images, which decreases the limitation in the hours of operation (Ortega-Terol et al. 2017); and 4) the point cloud generated is much more accurate, making it possible to obtain the geometric characteristics of the plants, which can improve crop monitoring (Ballesteros et al. 2015).

The GCC is considered to be a geometric parameter that provides information about vegetative growth level or canopy vigor. The GCC is usually related with biomass and plant height, but in this study, GCC was related to $\mathrm{S}_{\psi}$. Better results were obtained in 2018 than in 2019.

The best-calibrated model, which used GLI and computed $\mathrm{S}_{\psi}$ data on 23 Aug 2018 with 1394 GDD, was validated with GLI data from a date in 2019 with similar GDD (28 Aug 2019 with 1468 GDD). The weak performance of the model generated one year and applied to the next suggests that it is necessary to make complementary use of field measurements with UAV flights every irrigation season. The implementation of the proposed methodology does not avoid using field measurements such as pressure chamber measurements. However, it allows applying results obtained in just a few points of the plot to the whole plot. Because water potential determinations have to be carried out within a short time (i.e., one hour) to avoid the differential effects of varying environmental conditions during the day, the procedure developed here could be used to map the entire vineyard water status variability from a few on-the-ground point determinations. This is of particular interest for both obtaining a more representative evaluation of the entire vineyard water status and determining different zones within the vineyard. Nevertheless, obtaining aerial images from veraison to senesce may be enough to monitor differences in water status. All calibrated models for both seasons showed better performance in the last sampling dates when the fruit development was at veraison and differences in water status were observed. This was more significant for GLI performance, as previously mentioned, on 23 Aug 2018 at 1394 GDD. However, field measurements are necessary to quantify differences in water status. It is important to highlight that monitoring water status depends on the rain regime, irrigation scheduling, and crop development, making it necessary to determine the most appropriate flight starting date for every individual case.

\section{Conclusion}

The use of RGB cameras onboard a UAV platform made it possible for us to obtain high spatial resolution images for monitoring grapevine water status with better results than when using (more complex) multispectral images. This, together with occasional pressure chamber measurements, enables the monitoring of water status throughout the entire vineyard. The use of conventional RGB cameras increases the applicability of the proposed methodology because of the lower cost of the system and easier photogrammetric treatment compared with multispectral and thermal products. Moreover, the results from 2018 showed that canopy growth (represented by GCC obtained from the RGB camera) also had a good correlation with grapevine water status; therefore, it can be used as a predictor for the midterm effects of water deficit.

Because of the poor results obtained when a model calibrated for one season is applied to another season, it can be concluded that it is necessary to generate a new empirical model for every season. Nevertheless, only flights close to veraison were necessary in the case study, reducing the number of required flights and, therefore, the cost of application.

Future advances will be focused on implementing other statistical regression models, such as machine learning techniques, to enhance the obtained fits. Furthermore, more efforts will be made to predict the water status in a specific date of any year using a previous generalizable calibrated model by extending the number of analyzed seasons.

\section{Literature Cited}

Acevedo-Opazo C, Tisseyre B, Ojeda H, Ortega-Farias S and Guillaume S. 2008a. Is it possible to assess the spatial variability of vine water status? OENO One 42:203-219.

Acevedo-Opazo C, Tisseyre B, Guillaume S and Ojeda H. 2008b. The potential of high spatial resolution information to define withinvineyard zones related to vine water status. Precis Agric 9:285-302.

Acevedo-Opazo C, Ortega-Farias S and Fuentes S. 2010. Effects of grapevine (Vitis vinifera L.) water status on water consumption, vegetative growth and grape quality: An irrigation scheduling application to achieve regulated deficit irrigation. Agr Water Manage 97:956-964.

Amerine MA and Winkler AJ. 1944. Composition and quality of musts and wines of California grapes. Hilgardian 15:493-675.

Baggiolini M. 1952. Les stades repères dans le développment annuel de la vigne et leur utilisation pratique. Rev Rom d'Agriculture d'Arboriculture 8:4-6. 
Ballesteros R, Ortega JF, Hernández D and Moreno MA. 2014. Applications of georeferenced high-resolution images obtained with unmanned aerial vehicles. Part I: Description of image acquisition and processing. Precis Agric 15:579-592.

Ballesteros R, Ortega JF, Hernández D and Moreno MÁ. 2015. Characterization of Vitis vinifera L. canopy using unmanned aerial vehicle-based remote sensing and photogrammetry techniques. Am J Enol Vitic 66:120-129.

Ballesteros R, Ortega JF, Hernandez D and Moreno MA. 2018. Onion biomass monitoring using UAV-based RGB imaging. Precis Agric 19:840-857.

Baluja J, Diago MP, Balda P, Zorer R, Meggio F, Morales F and Tardaguila J. 2012. Assessment of vineyard water status variability by thermal and multispectral imagery using an unmanned aerial vehicle (UAV). Irrig Sci 30:511-522.

Berni J, Zarco-Tejada PJ, Suárez L and Fereres E. 2009. Thermal and narrowband multispectral remote sensing for vegetation monitoring from an unmanned aerial vehicle. IEEE Trans Geosci Remote Sens 47:722-738.

Boukoberine MN, Zhou Z and Benbouzid M. 2019. A critical review on unmanned aerial vehicles power supply and energy management: Solutions, strategies, and prospects. Appl Energ 255:113823.

Buesa I, Pérez D, Castel J, Intrigliolo DS and Castel JR. 2017. Effect of deficit irrigation on vine performance and grape composition of Vitis vinifera L. cv. Muscat of Alexandria. Aust J Grape Wine Res 23:251-259.

Chen JM. 1996. Evaluation of vegetation indices and a modified simple ratio for boreal applications. Can J Remote Sens 22:229-242.

Climate zones. National Geographic Institute (NGI). 2020. as found on the website (https://www.ign.es/espmap/mapas_clima_bach/pdf/ Clima_Mapa_1_2texto.pdf).

Córcoles JI, Ortega JF, Hernández D and Moreno MA. 2013. Estimation of leaf area index in onion (Allium cepa L.) using an unmanned aerial vehicle. Biosyst Eng 115:31-42.

Costa JM, Grant OM and Chaves MM. 2010. Use of thermal imaging in viticulture: Current application and future prospects. In Methodologies and Results in Grapevine Research. Delrot S et al. (eds.), pp. 135-150. Springer Science+Business Media B.V., Dordrecht.

Daughtry CST, Walthall CL, Kim MS, de Colstoun EB and McMurtrey III JE. 2000. Estimating corn leaf chlorophyll concentration from leaf and canopy reflectance. Remote Sens Environ 74:229-239.

Gitelson AA. 2011. Nondestructive estimation of foliar pigment (chlorophylls, carotenoids and anthocyanins) contents: Evaluating a semianalytical three-band model. In Hyperspectral Remote Sensing of Vegetation. Thenkabail PS et al. (eds.), pp. 141-166. CRC Press, Boca Raton, FL.

Gitelson AA and Merzlyak MN. 1998. Remote sensing of chlorophyll concentration in higher plant leaves. Adv Space Res 22:689-692.

Gitelson AA, Kaufman YJ, Stark R and Rundquist D. 2002. Novel algorithms for remote estimation of vegetation fraction. Remote Sens Environ 80:76-87.

Haboudane D, Miller JR, Tremblay N, Zarco-Tejada PJ and Dextraze L. 2002. Integrated narrow-band vegetation indices for prediction of crop chlorophyll content for application to precision agriculture. Remote Sens Environ 81:416-426.

Haboudane D, Miller JR, Pattey E, Zarco-Tejada PJ and Strachan IB. 2004. Hyperspectral vegetation indices and novel algorithms for predicting green LAI of crop canopies: Modeling and validation in the context of precision agriculture. Remote Sens Environ 90:337-352.

Hernandez-Lopez D, Felipe-Garcia B, Gonzalez-Aguilera D and AriasPerez B. 2013. An automatic approach to UAV flight planning and control for photogrammetric applications: A test case in the Asturias region (Spain). Photogramm Eng Rem S 79:87-98.
Intrigliolo DS and Castel JR. 2010. Response of grapevine cv. 'Tempranillo' to timing and amount of irrigation: Water relations, vine growth, yield and berry and wine composition. Irrig Sci 28:113.

Jackson DI and Lombard PB. 1993. Environmental and management practices affecting grape composition and wine quality - A review. Am J Enol Vitic 44:409-430.

Jordan CF. 1969. Derivation of leaf area index from quality of light on the forest floor. Ecology 50:663-666.

Kawashima S and Nakatani M. 1998. An algorithm for estimating chlorophyll content in leaves using a video camera. Ann Bot 81:49-54.

Louhaichi M, Borman MM and Johnson DE. 2001. Spatially located platform and aerial photography for documentation of grazing impacts on wheat. Geocarto Int 16:65-70.

Mao W, Wang Y and Wang Y. 2003. Real-time detection of betweenrow weeds using machine vision. doi: 10.13031/2013.15381. ASABE Annual Meeting. Las Vegas, NV.

Matese A and Di Gennaro SF. 2015. Technology in precision viticulture: A state of the art review. Int J Wine Res 7:69-81.

Mirás-Avalos JM and Intrigliolo DS. 2017. Grape composition under abiotic constrains: water stress and salinity. Front Plant Sci 8:851.

Möller M, Alchanatis V, Cohen Y, Meron M, Tsipris J, Naor A, Ostrovsky V, Sprintsin M and Cohen S. 2007. Use of thermal and visible imagery for estimating crop water status of irrigated grapevine. J Exp Bot 58:827-838.

Ortega-Terol D, Hernandez-Lopez D, Ballesteros R and GonzalezAguilera D. 2017. Automatic hotspot and sun glint detection in UAV multispectral images. Sensors-Basel 17:2352.

Pádua L, Vanko J, Hruška J, Adão T, Sousa JJ, Peres E and Morais R. 2017. UAS, sensors, and data processing in agroforestry: A review towards practical applications. Int J Remote Sens 38:2349-2391.

Poblete T, Ortega-Farías S, Moreno MA and Bardeen M. 2017. Artificial neural network to predict vine water status spatial variability using multispectral information obtained from an unmanned aerial vehicle (UAV). Sensors 17:2488.

Pôças I, Rodrigues A, Gonçalves S, Costa PM, Gonçalves I, Pereira LS and Cunha M. 2015. Predicting grapevine water status based on hyperspectral reflectance vegetation indices. Remote Sens 7:16460-16479.

Qi J, Chehbouni A, Huete AR, Kerr YH and Sorooshian S. 1994 A modified soil adjusted vegetation index. Remote Sens Environ 48:119-126.

Ribeiro-Gomes K, Hernandez-Lopez D, Ballesteros R and Moreno MA. 2016. Approximate georeferencing and automatic blurred image detection to reduce the costs of UAV use in environmental and agricultural applications. Biosyst Eng 151:308-327.

Rodríguez-Pérez JR, Riaño D, Carlisle E, Ustin S and Smart DR. 2007. Evaluation of hyperspectral reflectance indexes to detect grapevine water status in vineyards. Am J Enol Vitic 58:302-317.

Romero M, Luo Y, Su B and Fuentes S. 2018. Vineyard water status estimation using multispectral imagery from an UAV platform and machine learning algorithms for irrigation scheduling management. Comput Electron Agr 147:109-117.

Romero P, Fernández-Fernández JI and Martinez-Cutillas A. 2010. Physiological thresholds for efficient regulated deficit-irrigation management in winegrapes grown under semiarid conditions. Am J Enol Vitic 61:300-312.

Romero-Trigueros C, Nortes PA, Alarcón JJ, Hunink JE, Parra M, Contreras S, Droogers P and Nicolás E. 2017. Effects of saline reclaimed waters and deficit irrigation on Citrus physiology assessed by UAV remote sensing. Agric Water Manag 183:60-69.

Rossini M et al. 2013. Assessing canopy PRI from airborne imagery to map water stress in maize. ISPRS J Photogramm 86:168-177. 
Roujean JL and Breon FM. 1995. Estimating PAR absorbed by vegetation from bidirectional reflectance measurements. Remote Sens Environ 51:375-384.

Rouse J, Haas RH, Deering DW, Schell JA and Harlan J. 1973. Monitoring the Vernal Advancement and Retrogradation (Green-Wave Effect) of Natural Vegetation. National Aeronautics and Space Administration (NASA), U.S.

Saberioon MM, Amin MSM, Anuar AR, Gholizadeh A, Wayayok A and Khairunniza-Bejo S. 2014. Assessment of rice leaf chlorophyll content using visible bands at different growth stages at both the leaf and canopy scale. Int J Appl Earth Obs 32:35-45.

Santesteban LG et al. 2019. Discrimination ability of leaf and stem water potential at different times of the day through a meta-analysis in grapevine (Vitis vinifera L.). Agr Water Manage 221:202-210.
Viña A and Gitelson AA. 2011. Sensitivity to foliar anthocyanin content of vegetation indices using green reflectance. IEEE Geosci Remote S 8:464-468.

Zarco-Tejada PJ, Berjón A, López-Lozano R, Miller JR, Martín P, Cachorro V, González MR and de Frutos A. 2005. Assessing vineyard condition with hyperspectral indices: Leaf and canopy reflectance simulation in a row-structured discontinuous canopy. Remote Sens Environ 99:271-287.

Zarco-Tejada PJ, González-Dugo V, Williams LE, Suárez L, Berni JAJ, Goldhamer D and Fereres E. 2013. A PRI-based water stress index combining structural and chlorophyll effects: Assessment using diurnal narrow-band airborne imagery and the CWSI thermal index. Remote Sens Environ 138:38-50. 